\title{
Polypropylene Matrix Composites Reinforced with Coconut Fibers
}

\author{
Maria Virginia Gelfuso ${ }^{\mathrm{a} *}$, Pedro Vieira Gurgel da Silva ${ }^{\mathrm{b}}$, Daniel Thomazini ${ }^{\mathrm{a}}$ \\ ${ }^{a}$ Instituto de Engenharia Mecânica, Universidade Federal de Itajubá - UNIFEI, \\ Av. BPS, 1303, CEP 37500-903, Itajubá, MG, Brazil \\ ${ }^{b}$ Engenharia de Controle e Automação, Universidade de Fortaleza - UNIFOR, \\ Av. Washington Soares, 1321, Edson Queiroz, CEP 60811-905, Fortaleza, CE, Brazil
}

Received: March 16, 2011; Revised: June 21, 2011

\begin{abstract}
Polypropylene matrix composites reinforced with treated coconut fibers were produced. Fibers chemically treated (alkalization-CCUV samples) or mechanically treated (ultrasonic shockwave-CMUV samples) were dried using UV radiation. The goal was to combine low cost and eco-friendly treatments to improve fiber-matrix adhesion. Composite samples containing up to $20 \mathrm{vol}$. (\%) of untreated and treated coconut fibers were taken from boxes fabricated by injection molding. Water absorption and mechanical properties were investigated according to ASTM D570-98 and ASTM D638-03, respectively. Electrical characterizations were carried out to identify applications of these composites in the electrical sector. NBR 10296-Electrical Tracking Standard (specific to industry applications) and conductivity measurements were obtained applying $5 \mathrm{kV} \mathrm{DC}$ to the samples. CMUV samples containing $5 \mathrm{vol}$. (\%) fiber presented superior tensile strength values $(\sigma \sim 28 \mathrm{MPa})$ compared to the untreated fibers composite $(\sigma \sim 22 \mathrm{MPa})$ or alkali treatment $(\sigma \sim 24 \mathrm{MPa})$. However, CMUV composites containing $10 \mathrm{vol}$. $(\%)$ fiber presented best results for the electrical tracking test and electrical resistivity $\left(3 \times 10^{7} \Omega\right.$.m). The results suggest that composites reinforced with mechanically treated coconut fibers are suitable for electrical applications.
\end{abstract}

Keywords: coconut fiber, composite, mechanical properties, polypropylene

\section{Introduction}

Polymeric composites reinforced with natural fibers have become a topic of interest during the last decades ${ }^{1}$. Natural fiber composite materials have gained importance and popularity due to their lightweight, high strength, stiffness, corrosion resistance, and lower impact on the environment ${ }^{2}$. Because of their quality, durability and other advantages, they are used to make a wide variety of floor mats, yarn, rope, etc ${ }^{3}$. In some cases, natural fibers can be obtained as a by-product of the coconut fruit, for example. The traditional products consume only a small percentage of the total world production of coconut husks that is generated by the food industry and coastal touristic regions. Thus, research and development efforts have been carried out to find new uses for coir, including its utilization as reinforcement in polymer composites in automotive parts, household and electrical applications. However, a high level of moisture absorption and insufficient adhesion between untreated fibers and the polymer matrix may lead to bio-composites presenting high water absorption and poor mechanical properties that reduce their use in electrical devices.

Several fiber surface treatment methods have been studied to improve the adhesion between coconut fibers and the surrounding matrix, as well as, to reduce water absorption and increase mechanical properties. Nowadays, effective methods based on chemical treatment ${ }^{4,5}$ such as dewaxing and grafting are used to increase the surface area available for contact with the matrix, but these methods are expensive (like silane agents) and they may cause serious damage to the environment (acids or alkalis agents). Alkalization is the main technique used on natural fiber to remove hemicelluloses ${ }^{6}$ of fiber surfaces and it has been employed as a less harmful treatment to the environment and cheaper than other methods proposed. However, its use is still controversial, some are favorable ${ }^{7}$ others suggest controlled application ${ }^{8}$ mainly due to chemical wastes generated. Physical treatments (cold plasma treatment, corona treatment $)^{9,10}$ have been proposed as eco friendly processes for superficial modification of the fibers, but these are usually complex and very expensive methodologies. Research on an effective low cost treatment of natural fibers is necessary since the cost of the raw material, i.e. the natural fiber, is very attractive to the market. Some studies have been carried out on photo-induced grafting onto cellulose ${ }^{11-13}$ employing UV radiation. Rahman and Mubarak ${ }^{14}$, for instance, applied artificial UV radiation as a pretreatment on coconut fibers reinforced polymethacrylate matrix. The authors observed an increase in the tensile properties and they attributed this effect to the inter-crosslinking between the neighboring cellulose molecules that occurs under UV radiation. The surface topography is entirely modified after this treatment suggesting that a mechanical treatment could successfully enhance fiber-matrix adhesion. Although the combination of mechanical and UV radiation treatments represents a new and simple proposal that can be employed to enhance physicomechanical properties of coconut fiber composite based on polymeric matrix, no study has been reported up to now.

Despite the attractiveness of natural fiber reinforced polymer matrix composites and the problem related to fiber-matrix adhesion, manufacturing processes have not been explored in order to enhance industrial productivity of such composites. Injection molding is the main method used by the plastic industry due to its high efficiency and low cost. The combination of injection techniques and natural fiber, especially coconut fiber, to manufacture industrial products has not been sufficiently investigated. As far as these issues are concerned, a balance between performance and technological applications of composite material might be achieved through proper methodology. 
Therefore, the present study proposes combined low cost and eco-friendly treatments in order to improve fiber-matrix adhesion. The fibers were submitted to surface modifications such as alkali or mechanical treatment, followed by UV ageing (sun light exposure) to dry and help to improve the fiber-matrix adhesion. Boxes made of coconut fiber-reinforced polypropylene matrix composites containing up to 20 vol. (\%) of fibers (PP-Fiber), untreated, mechanically (ultrasonic shockwave) and chemically treated (2 wt. (\%) $\mathrm{NaOH}$, $25{ }^{\circ} \mathrm{C}$ ) were fabricated by injection molding. Alkalization, using only 2 wt. (\%) $\mathrm{NaOH}$, and ultrasonic shockwave treatments were chosen to modify the coconut fiber in order to develop a cheaper and less toxic method and thus, attend to fabrication on industrial scale. Polypropylene (PP) was used for some reasons: first, it is easy to process and one of the cheapest industrial polymers in the market which is of significant importance to the 'cost-performance' assessment; second, it requires a low processing temperature, which is essential because of the relatively low thermal stability of natural fibers $\left(200-250{ }^{\circ} \mathrm{C}\right)$. Thus, since knowledge of mechanical and electrical properties as well as water absorption behavior are essential to evaluate the use of this material in electrical devices, studies about these properties were conducted on this work.

\section{Experimental Procedure}

\subsection{Fiber surface treatment}

Coir mesh matting supplied by EMBRAPA (Empresa Brasileira de Pesquisa Agropecuária - Fortaleza, CE, Brazil) is produced from a process based on drying, grinding, and sorting of fibers starting from green coconut shells ${ }^{15}$.

The matting was nonwoven and no adhesive agent was used to form a $1 \mathrm{~mm}$ thick mesh. After that, the matting was treated with 2 wt. (\%) $\mathrm{NaOH}$ solution for 2 hours at $25^{\circ} \mathrm{C}$, followed by washing with distilled water several times to leach out the absorbed alkali and finally dried in oven at $70{ }^{\circ} \mathrm{C}$. Thus, the fibers obtained were known as dewaxed or defatted fibers. The defatted fibers were treated under solar irradiation (UV) for 24 hours. The time of solar irradiation considered to treatment started at 9:00 AM and went on until 4:00 PM.

Another set of matting was submitted to mechanical treatment based on ultrasonic shockwave. In this case, an Ultrasonic Processor model VC 505 with $500 \mathrm{~W}$ power was used to produce some erosion on the fiber surface. To obtain this effect, the matting was immersed in water and the ultrasonic probe was introduced into the container. An Ultrasonic Processor operated for 1 and 2 hours, and then the mat was dried in oven at $70{ }^{\circ} \mathrm{C}$. After that, the mat was exposed to solar radiation (UV) for 24 hours, at the same time as the first set.
The composites produced by chemical treatment followed by UV radiation were called CCUV and the second set treated by the mechanical method was named CMUV.

\subsection{Composite preparation}

Figure 1 shows the physical aspect of the mat at different steps of the composites preparation. Several coconut fiber mats (Figure 1a) were cut out, stacked, and uniaxially pressed just to shape a coir box (Figure 1b). After that, this coir box was placed inside a mold to perform the PP injection and produce the composite (Figure 1c).

The thermoplastic polymer polypropylene (PP), used as matrix material, was supplied by Braskem S.A. (São Paulo-Brazil) in the form of homopolymer pellets. It presented $0.90-0.91$ specific gravity, $165-171{ }^{\circ} \mathrm{C}$ melting temperatures and $82 \%$ crystallinity.

Coconut fiber-polypropylene composite boxes containing up to 20 vol. (\%) of coir fibers were formed by injection molding. For the injection molding, a HAITIAN- SA2500/1000 B injection machine was used, working with $105.7 \mathrm{MPa}$ injection pressure at $175^{\circ} \mathrm{C}$. Composites containing untreated fiber were produced and analyzed to compare the efficiency of the proposed treatments.

\subsection{Mechanical testing}

Tensile tests were performed using an Instron-Model 4484, in accordance to ASTM D638-03. The displacement of the sample was measured with a $50 \mathrm{~mm}$ extensometer. The specimens were tested at a transversal displacement rate of $5 \mathrm{~mm} / \mathrm{min}$ and the tensile strength was obtained from the engineering stress-strain curve.

\subsection{Water absorption}

Water absorption values of treated and untreated fibers were determined according to ASTM D 570-98(2005). Based on this standard, the samples were placed into a container with distilled water at room temperature, and the water uptake for different swelling times was measured. For each type of composite, four specimens were tested and the average values were reported. All samples, for all the tests were extracted from the bottom side of the boxes.

\subsection{Electrical testing}

\subsubsection{Resistance to electrical tracking}

A study of the electrical properties of the composites was carried out to identify applications of the composites in the electrical sector. NBR 10296 (May/1988) namely Electrical Insulating MaterialEvaluating Resistance to Tracking and Erosion under Severe Ambient Conditions ${ }^{16}$ is a Brazilian standard test method very

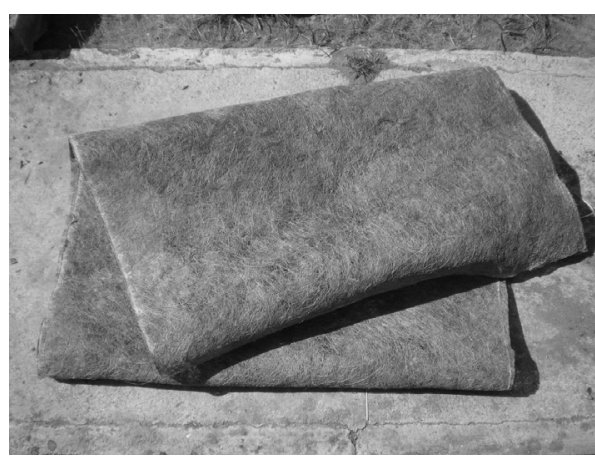

(a)

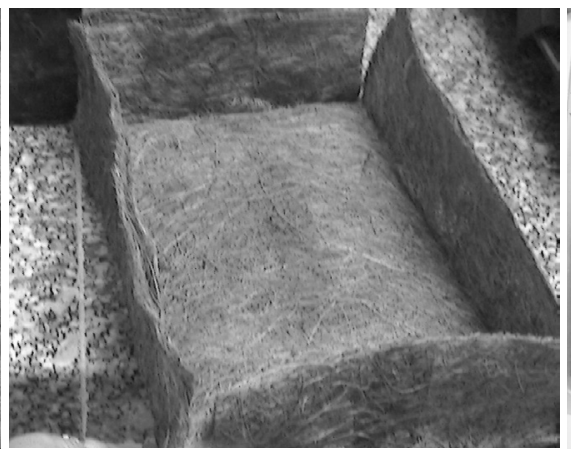

(b)

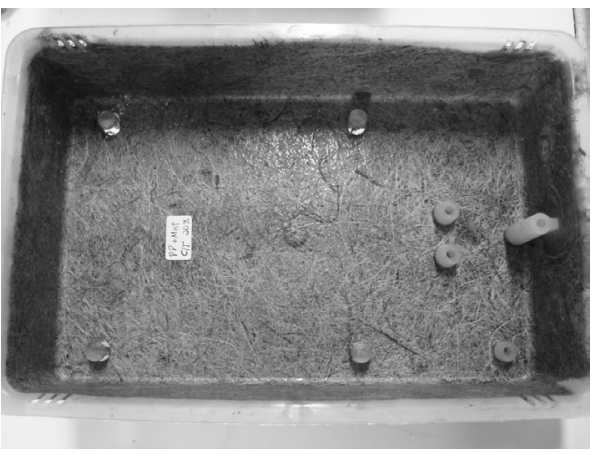

(c)

Figure 1. Physical aspect of the mat at different steps of the composites preparation. a) Raw mat; b) Box-shaped mat; and c) PP-Fiber composite injected. 
similar to the International ASTM D3638-07-Standard Test Method for Comparative Tracking Index of Electrical Insulating Materials. However, NBR 10296 or Electrical Tracking standard is more specific to industry applications. As this study is part of a project whose main goal is the production of boxes applied to the electrical sector, these tests were performed using an experimental setup defined in such standard. Figure 2 shows a schematic diagram of the experimental set-up used in the present study. It is recommended to test five $50.0 \mathrm{~mm} \times 120.0 \mathrm{~mm}$ samples. A corrosive solution based on $\mathrm{NH}_{4} \mathrm{Cl}(0.1 \mathrm{M})$ is dropped with $0.9 \mathrm{~mL} / \mathrm{min}$ on the paper filter which is simultaneously connected to an upper electrode and to the sample. The corrosive fluid flows over the surface of the sample and an electric voltage of $5.0 \mathrm{kV}$ DC is applied to the electrodes (separated by $50.0 \pm 0.5 \mathrm{~mm}$ ) that are attached to the sample. The samples are kept under this voltage for 6.0 hours, without rupture or until the electrical path in the specimen leaves a mark $25.0 \mathrm{~mm}$ from the lower electrode. In this case, NBR 10296 predicts that the classification of material meets the criterion $\mathrm{B}$, which is the most suitable for evaluating materials that will be subject to conditions of high electric fields. Other classifications can be found in NBR10296, but do not apply to this case study.

\subsubsection{Electrical conductivity evaluation}

Square specimens of 50.0 and $3.0 \mathrm{~mm}$ thickness were put between copper plates, which were used as electrodes. An electric voltage of $5.0 \mathrm{kV} \mathrm{DC}$ was applied to the samples to obtain the electrical resistance measurements, and finally, the electrical conductivity values were calculated.

\section{Results and Discussion}

\subsection{Mechanical strength}

Figure 3 shows the tensile strength of the $\mathrm{NaOH}$ treated coir fiber reinforced PP Fiber-composites (CCUV) and ultrasonic treated fiber (CMUV) at different fiber loading. The tensile test value of untreated fiber reinforced PP fiber-composites is presented to compare the results with those obtained for CCUV and CMUV. As the fiber load increased, the weak interfacial area between the fiber and matrix increased, consequently, the tensile strength decreased ${ }^{17}$. This behavior could be observed for all the samples, treated and untreated. Indicula et al. ${ }^{18}$, found similar results and suggested that the high loading of coconut fiber leads to agglomeration and stress transfer becoming blocked, and as result, mechanical strength decreases.

Comparing the superficial treatments, it was observed that the alkali treatment did not improve fiber-matrix adhesion. It is well known that this treatment is able to remove the natural and artificial impurities from the fiber surface as well as change the crystal structure of the cellulose ${ }^{19}$. Moreover, depending on the concentration of the alkali treatment, it can reduce fiber diameter and thereby composite tensile strength decreases. Also, the $\mathrm{NaOH}$ modifications may decrease the strength due to the breakage of the bond structure, and also because of the disintegration of the non-cellulosic materials ${ }^{20}$. Another consequence of the chemical treatment is an unlocking of the hydrogen bonds making them more reactive. In the untreated state the cellulosic-OH groups are relatively unreactive as they form strong hydrogen bonds. In addition to this, alkali treatment can lead to fibrillation, i.e., breaking down of fibers into smaller ones.

On the other hand, tensile strength values of CMUV composites were higher than those of the CCUV, independent of fiber loading. This effect can be associated to the friction occurred between the fibers during the mechanical treatment by ultrasonic shockwave. This friction promotes the wear of fiber surface and develops a

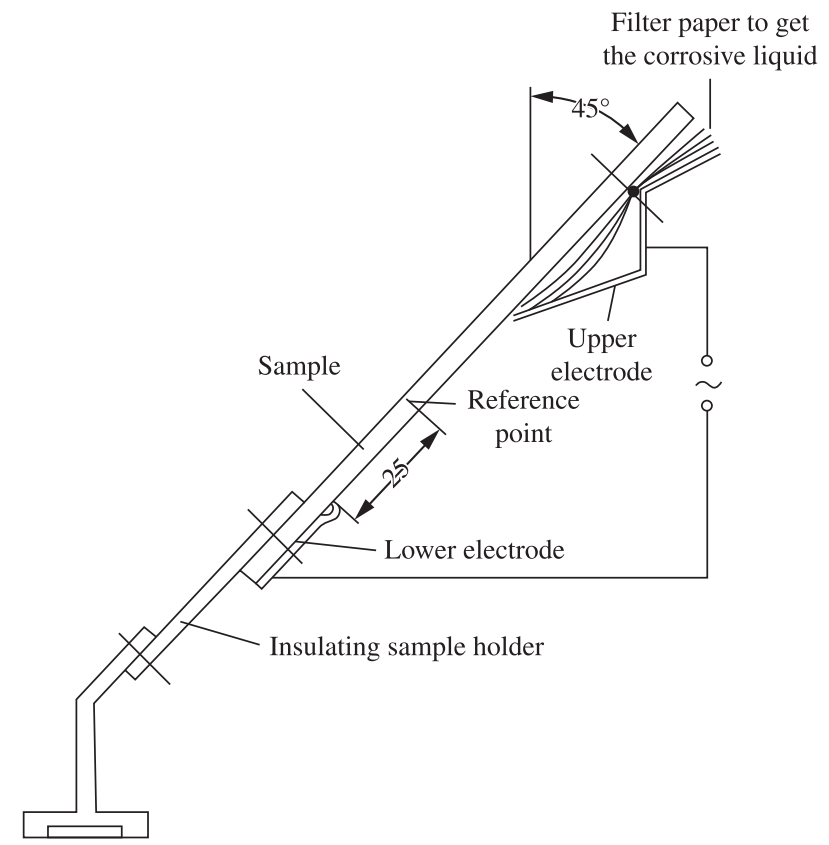

Figure 2. Schematic diagram of the experimental set-up used in the electrical tracking test.

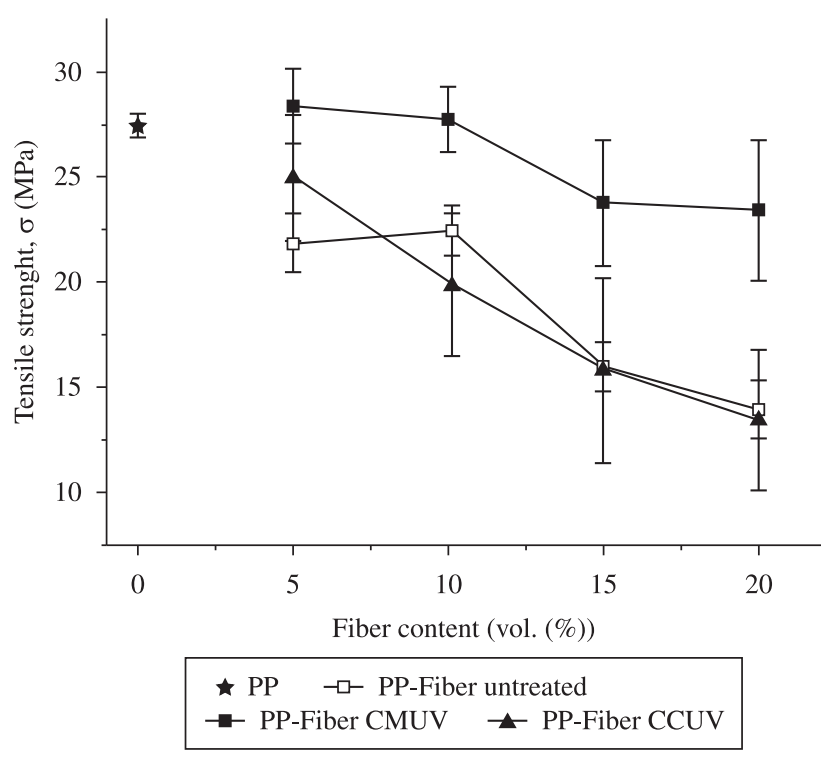

Figure 3. Tensile strength of the PP-Fiber composites, untreated, CMUV and CCUV samples.

rough surface topography increasing the mechanical interlocking with matrix and thus, it enhances fiber-matrix interface adhesion and amplifies the mechanical properties ${ }^{21}$. However, the strength tensile decreases as the interactions fiber-fiber increase instead of fiber-matrix. The highest tensile strength value $(28.42 \pm 1,78 \mathrm{MPa})$ was observed for the CMUV sample containing 10 vol. (\%) fiber.

\subsection{Water absorption results}

Water absorption values of untreated composites (Figure 4a), CMUV (Figure 4b) and CCUV (Figure 4c) are shown. Water absorption slightly increased with an increase in fiber loading for 


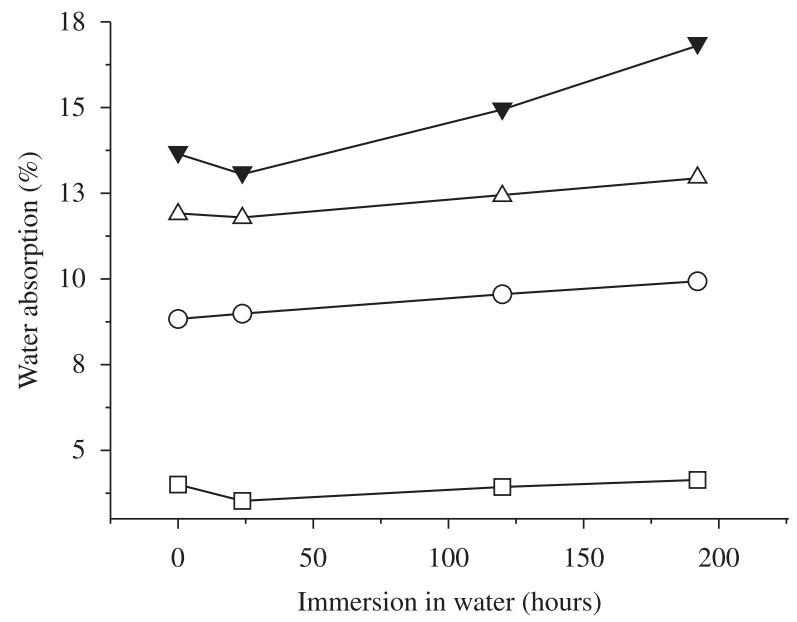

(a)

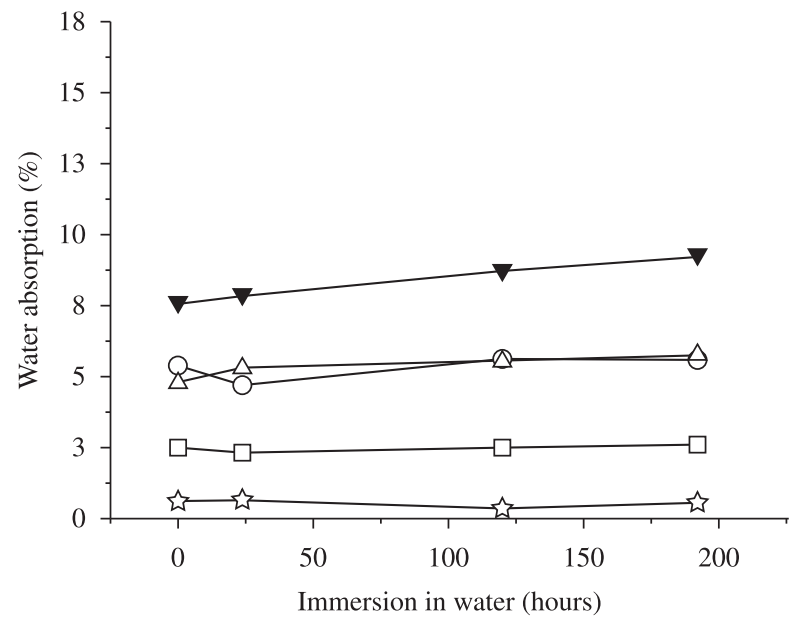

(b)

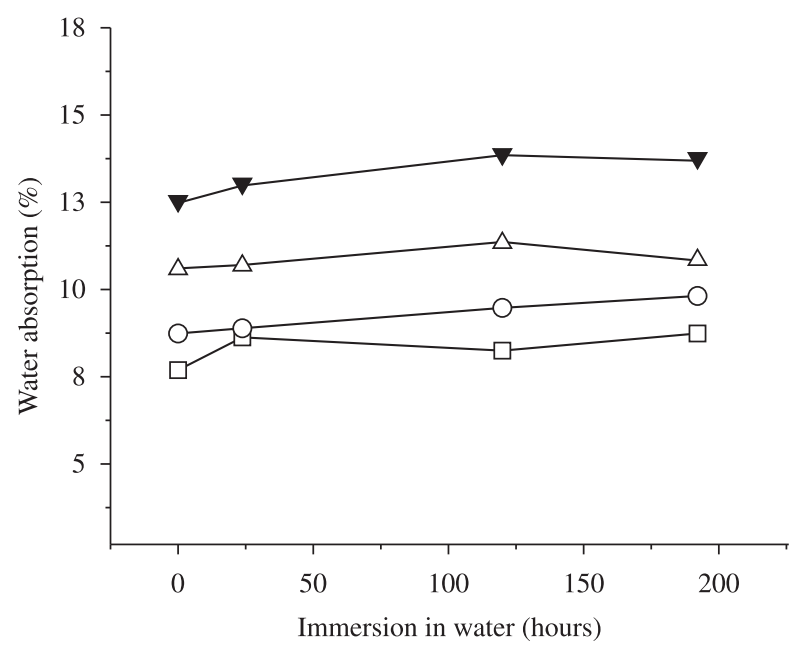

(c)

Figure 4. Water absorption of a) untreated fiber; b) mechanically treated PP-Fiber (CMUV); and c) chemically treated PP-Fiber composites (CCUV).

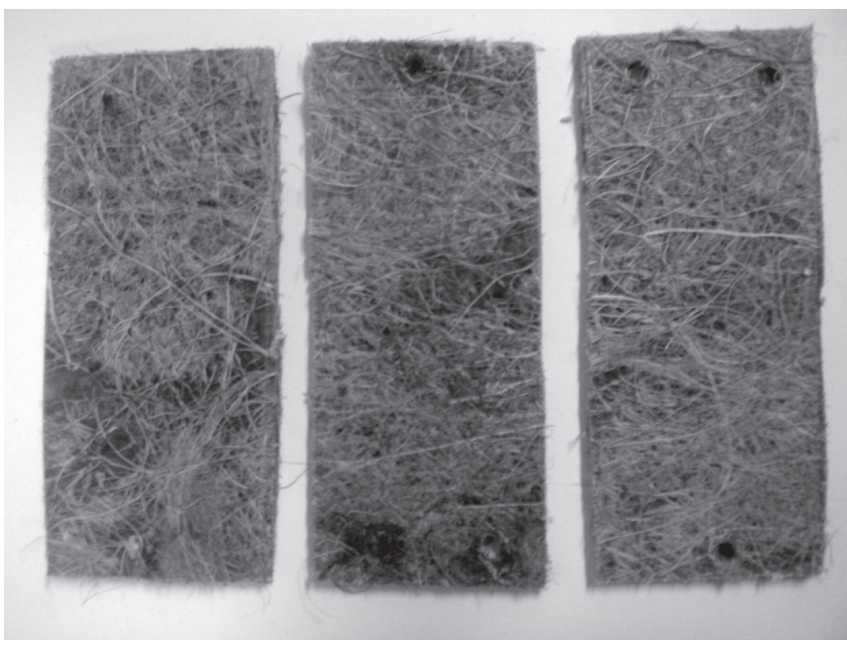

Figure 5. Visual aspect of the PP-Fiber composites after electrical tracking tests. From left to right: CMUV, untreated and CCUV samples.

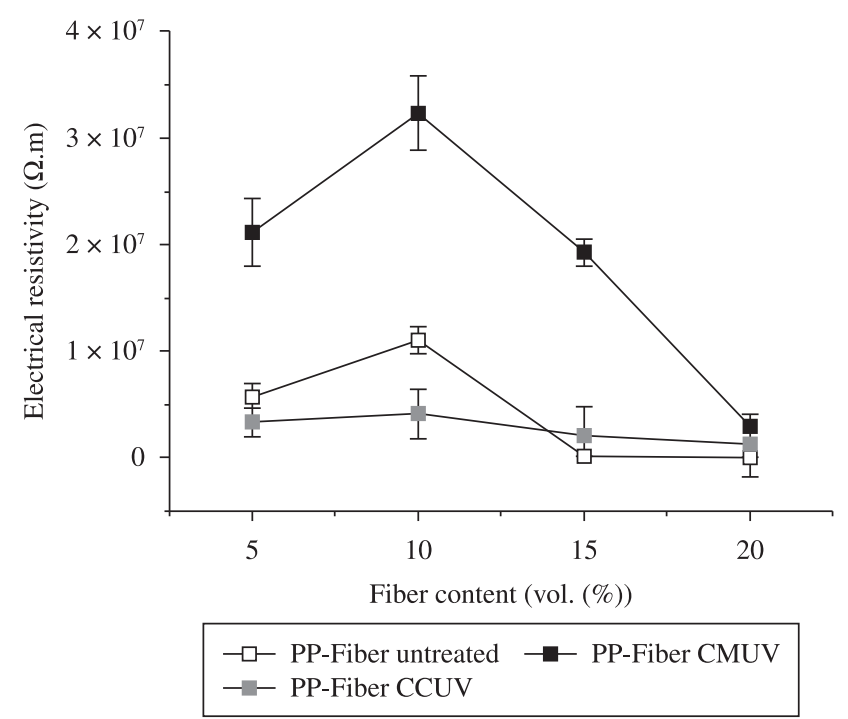

Figure 6. Electrical resistivity of the PP-Fiber composites, untreated, CMUV and CCUV samples.

all cases, in accordance to Yang 22 . As a consequence of fiber load increase in the matrix, there were significant void spaces introduced into the polymeric matrix resulting in a higher interaction fiber-fiber instead of fiber-matrix.

It is known that hydroxyl groups present on the surface of the fibers are responsible for water absorption ${ }^{23}$. As the superficial treatment decreased the number of hydroxyl groups, the water uptake was reduced in the treated samples. In other words, the reduction in $\mathrm{OH}$ groups of cellulose reduced the hydrophilic character of the fibers. In the untreated state the cellulosic-OH groups are reactive and they form strong hydrogen bonds being able to retain water.

The CCUV samples presented higher water absorption (13\%) than CMUV samples $(\sim 7 \%)$ indicating that this alkali treatment was inefficient to remove the - $\mathrm{OH}$ groups on the surface of treated fibers causing higher water retention. Conversely, the surface modification by ultrasonic shockwave promoted a better mechanical interlocking between the fiber and matrix, and thus water absorption was lower for CMUV samples. 


\subsection{Effect of chemical modification on the electrical tracking test}

The study of the electrical conductivity of the insulating material is important because the most desirable property of an insulator is its ability to resist to electric current leakage. Figure 5 shows the visual aspect of the PP-Fiber composites after the electrical tracking test. In the sequence, on the left, it can be seen that CMUV sample did not present damage by carbonization, as opposed to untreated composite fiber (in the middle). For the CCUV sample also no superficial carbonization was observed. As explained previously, the presence of -OH groups on these surface fibers causes high water absorption forming an electrical current path and thus, a carbonizing track is formed on the sample surface. This undesirable effect was eliminated by both treatments.

Another interesting observation is that electrical resistivity of the composites decreased as the fiber load increased (Figure 6) in both cases, i.e. with or without superficial treatment. The fibers loading increase implies a high amount of polar group, and therefore there is a path to the electric current. Jacob et al. ${ }^{24}$ also reported similar results studying sisal fibers, observing that electrical resistivity of composites decreased as fiber loading increased. In this case, the fiber-fiber interaction was higher when the amount of fibers increased in the composites generating defects like empty spaces (pores or air bubbles). Composites containing amounts of fiber superior to $10 \%$ had electrical conductivity increased upon addition of lignocellulosic fibers due to the presence of polar groups, which facilitated the flow of electric current. The results observed in Figure 6 suggest that the optimal composite for electrical devices application must contain $10 \%$ fiber and mechanical treatment presented an environmentally friendly process to get better mechanical properties.

Also, it can be observed that CCUV composites presented the lowest values for electrical resistivity. According to Rahman ${ }^{14}$ the following reaction takes place as a result of alkali treatment:

$$
\text { Fiber- } \mathrm{OH}+\mathrm{NaOH} \rightarrow \text { Fiber- } \mathrm{O}-\mathrm{Na}^{+}+\mathrm{H}_{2} \mathrm{O}
$$

This reaction clearly shows that $\mathrm{Na}+$ ions can be present on the fiber surface after alkali treatment. This effect facilitates the transport of electrical charges and consequently promotes the decrease in electrical resistivity. Thus, this treatment is not suitable to produce composites designated to the electrical sector.

\section{Conclusions}

The mechanical properties of the fiber-reinforced polypropylene composites as a function of the fiber content (up to $20 \mathrm{vol}$. (\%)) and the surface treatment of fibers were evaluated. The surface fibers modifications were based on alkalization (CCUV composites) or mechanical treatment using ultrasonic shockwave (CMUV composites) and each treatment was followed by UV radiation to assure the application of an environmentally friendly process.

Regardless the fiber treatment, the tensile strength values decreased as the fiber content increased. The CMUV composites presented higher tensile strength than CCUV composites or those made of untreated fibers. This improvement is associated to the variation of the hydrophilic character of the treated fibers related to the reduction of polar component (-OH groups) and could be verified from water absorption results. As a consequence of the surface modifications, water absorption values of the CMUV samples were lower $(7 \%)$ than results obtained to untreated PP-Fiber (15\%) or CCUV composites (13\%). Electrical tracking and resistivity tests of the composites reflected the effect of this change on the surface of fibers. CMUV composites presented the best results for the electrical tracking test and higher electrical resistivity $\left(3 \times 10^{7} \Omega . \mathrm{m}-10 \%\right.$ of fiber) due to reduction of $-\mathrm{OH}$ groups present on the fiber surface. Thus, mechanical treatment based on ultrasonic shockwave followed by UV radiation showed to be an environmentally friendly process, producing composites suitable to be applied in the electrical sector.

\section{Acknowledgements}

This work is part of a project (ANEEL 0039-002/2007) founded by the Companhia Energética do Ceará-COELCE.

\section{References}

1. Garkhail SK, Heijenrath WH and Peijs T. Mechanical properties of natural-fibre-mat-reinforced thermoplastics based on flax fibres and polypropylene. Applied Composite Materials. 2000; 7:351-372. http://dx.doi.org/10.1023/A:1026590124038

2. Cantero G, Arbelaiz A, Llano-Ponte R and Mondragon I. Effects of fibre treatment on wettability and mechanical behavior of flax/polypropylene composites. Composites Science and Technology. 2003; 63:1247-1254. http://dx.doi.org/10.1016/S0266-3538(03)00094-0

3. Satyanarayan KG, Kulkarni AG and Rohatgi PK. Fabrication and properties of coir based composites. Journal of Scientific and Industrial Research. 1981; 40:222-229.

4. Mohanty AK, Misra M and Hinrichsen G. Biofibers biodegradable polymers and biocomposites: an overview. Macromolecular Materials and Engineering. 2000; 276-277:1-24. http://dx.doi.org/10.1002/(SICI)14392054(20000301)276:1\%3C1::AID-MAME1\%3E3.0.CO;2-W

5. Sanadi AR, Prasad SV and Rohtgi PK. Sunhempfibre-reinforced polyester. Journal of Materials Science. 1986; 21:4299-4304. http:// dx.doi.org/10.1007/BF01106545

6. Murali MRK and Mohana RK. Extraction of the tensile properties of natural fibers, Vakka, Date and Bambo. Journal of Composite Structures. 2007; 77:288-295. http://dx.doi.org/10.1016/j.compstruct.2005.07.023

7. Joseph S, Sreekala MS, Ommen Z, Kosy P and Thomas S. A comparison of mechanical properties of phenol formaldehyde composites reinforced with banana fibers and glass fibers. Composites Science and Technology. 2002; 62:1857-1868. http://dx.doi.org/10.1016/S0266-3538(02)00098-2

8. Bledzki AK and Gassan J. Composites reinforced with cellulose based fibers. Progress in Polymer Science. 1999; 24:221-274. http://dx.doi. org/10.1016/S0079-6700(98)00018-5

9. Luo $\mathrm{S}$ and Netravali A. Mechanical and thermal properties of environment-friendly "green" composites made from pineapple leaf fibres and poly(hydroxybutyrate-co-valerate) resin. Polymer Composites.1999; 20:367-378. http://dx.doi.org/10.1002/pc.10363

10. Ràcz I and Hargitai H. Influence of water on properties of cellulosic fibre reinforced polypropylene composites. International Journal of Polymeric Materials. 2000; 47:667-674. http://dx.doi.org/10.1080/00914030008031321

11. Hasan MM, Khan MA and Islam MR. Role of amino acids on in situ photografting of jute yarn with acrylamide using ultraviolet radiation. Polymer - Plastics Technology and Engineering. 2003; 42:515-531. http://dx.doi.org/10.1081/PPT-120024995

12. Ali KMI, Khan MA and Akhunzada KS. In situ jute yarn composite with HEMA via UV radiation. Journal of Applied Polymer Science. 1999; 71:841-846. http://dx.doi.org/10.1002/(SICI)10974628(19990131)71:5\%3C841::AID-APP19\%3E3.0.CO;2-6

13. Khan MA, Siraj MS, Rahman MM and Drzal LT. Improvement of mechanical properties of coir fiber (Cocusnucifera) with 2-hydroxyethylmethacrylate (HEMA) by photocuring. Polymer - Plastics Technology and Engineering. 2003; 42:253-267. http://dx.doi.org/10.1081/PPT-120017927

14. Rahman MM and Mubarak AK. Surface treatment of coir (Cocosnucifera) fibers and its influence onthe fibers' physico-mechanical properties. Composites Science and Technology. 2007; 67:2369-2376. http://dx.doi. org/10.1016/j.compscitech.2007.01.009

15. Carrijo OA, Liz RS and Makishima N. Fibra da casca de coco verde como substrato agrícola. Horticultura Brasileira. 2002; 20:533-535. http://dx.doi.org/10.1590/S0102-05362002000400003 
16. Associação Brasileira de Normas Técncicas - ABNT. NBR 10296: Electrical insulating material-evaluating resistance to tracking and erosion under severe ambient conditions-test method. ABNT; 1988. 12 p.

17. Yang HS, Kim HJ, Park HJ, Lee BJ and Hwang TS. Effect of compatibilizing agents on rice husk flour reinforced polypropylene composites. Composite Structures. 2007; 77:45-55. http://dx.doi.org/10.1016/j. compstruct.2005.06.005

18. Indicula M, Malhotrab SK, Joseph K and Thomas S. Dynamic mechanical analysis of randomly oriented intimately mixed short banana/sisal hybrid fiber reinforced polyester composites. Composites Science \& Technology. 2005; 65:1077-1087. http://dx.doi.org/10.1016/j. compscitech.2004.10.023

19. Mishra S, Misra M, Tripathy SS, Nayak SK and Mohanty AK. Potentiality of pineapple leaf fiber as reinforcement in PALF polyester composite: surface modification and mechanical performance. Journal of Reinforced Plastics and Composites. 2001; 20:321-334.

20. Sreekala MS, Kumaran MG, Joseph S, Jacob M and Thomas S. Oil palm fiber reinforced phenol formaldehyde composites: influence of fiber surface modifications on the mechanical performance. Applied Composite Materials. 2000; 7:295-329. http://dx.doi.org/10.1023/A:1026534006291

21. Mohanty AK, Misra M and Drzal LT. Surface modifications of natural fibers and performance of the resulting biocomposites: an overview. Composite Interfaces. 2001; 8:313-343. http://dx.doi.org/10.1163/156855401753255422

22. Yang HS, Kim HJ, Park HJ, Lee BJ and Hwang TS. Water absorption behavior and mechanical properties of lignocellulosic filler-polyolefin biocomposites. Composite Structures. 2006; 72:429-437. http://dx.doi. org/10.1016/j.compstruct.2005.01.013

23. Rahman MM and Khan MA. Surface treatment of coir (Cocosnucifera) fibers and its influence onthe fibers' physico-mechanical properties. Composites Science \& Technology. 2007; 67:2369-2376. http://dx.doi. org/10.1016/j.compscitech.2007.01.009

24. Jacob M, Varughese KT and Thomaz S. Dielectric Characteristic of SisalOil palm hybrid biofibre reinforced natural rubber biocomposites. Journal Materials Science. 2006; 41:5538-5547. http://dx.doi.org/10.1007/ s10853-006-0298-y 